\title{
Cardiac surgery in adults with congenital heart disease: an African perspective
}

\author{
Michael A Long ${ }^{1 *}$, Stephen C Brown ${ }^{2}$, Francis E Smit ${ }^{1}$, Sharon L Rossouw ${ }^{1}$ \\ From World Society of Cardiothoracic Surgeons 25th Anniversary Congress, Edinburgh \\ Edinburgh, UK. 19-22 September 2015
}

\section{Background/Introduction}

A paucity of data exists on the spectrum and outcome of adult patients undergoing congenital heart surgery (CHS) on the African continent.

\section{Aims/Objectives}

This study was undertaken to understand the local disease profile and needs of this patient group and so to facilitate planning for future provision of cardiac services.

\section{Method}

A retrospective chart review was undertaken of all consecutive adult patients ( $\leq 18$ years) undergoing CHS in a single African tertiary care hospital between October 1995 and January 2015. Patients and operative outcomes were described using the Society of Thoracic Surgeons CHS database form.

\section{Results}

A total of 220 operations were performed in 209 patients (45\% male). Mean age at surgery was $30,1 \pm$ 10,9 years. Preoperative diagnostic cardiac catheterization was performed in $86,3 \%$ of patients. The most common lesions according to primary diagnostic category were as follows: Septal defects $(43,6 \%)$, Right heart lesions, including Conduit failure (23,7\%), Left heart lesions $(10,5 \%)$ and Thoracic arteries and veins $(8,6 \%)$. Single ventricle lesions comprised $2,7 \%$ of diagnoses. Fifty-four percent of patients presented in the moderate or complex Bethesda diagnostic classes. Preoperative risk factors were present in 19,1\% of patients with endocarditis, renal dysfunction and severe pulmonary hypertension the most frequent. Reoperations constituted
$28,6 \%$ of procedures performed. Right ventricle to pulmonary artery conduit placement constituted $50,8 \%$ of the reoperations. Overall operative mortality was $1,8 \%$ $(\mathrm{n}=4)$ with $4,8 \%(\mathrm{n}=3)$ mortality in the reoperation group. Postoperative complications occurred in $26,8 \%$ of patients. The mean Aristotle Basic Score was 6,2 \pm 2.4 .

\section{Discussion/Conclusion}

Surgical treatment is feasible in the African context with low mortality and acceptable morbidity in spite of limited resources. Our patient profile was similar to that reported in a recent multicentre European series. Our utilization of diagnostic cardiac catheterization seemed excessive. More than half of our patient group will require long-term specialized care.

\begin{abstract}
Authors' details
${ }^{1}$ Department of Cardiothoracic Surgery, Faculty of Health Sciences, University of the Free State, PO Box 339 (Internal box G32), Bloemfontein, 9300, South Africa. ${ }^{2}$ Department of Paediatric Cardiology, Faculty of Health Sciences, University of the Free State PO Box 339 (Internal box G32), Bloemfontein, 9300, South Africa.
\end{abstract}

Published: 16 December 2015

doi:10.1186/1749-8090-10-S1-A323

Cite this article as: Long et al:: Cardiac surgery in adults with congenital heart disease: an African perspective. Journal of Cardiothoracic Surgery 2015 10(Suppl 1):A323. 